\title{
Free throw technical analysis and its relationship with success in Under-12 basketball players \\ Análisis técnico de los tiros libres y su relación con el éxito en jugadores de baloncesto menores de 12 años
}

*Álvaro Díaz-Aroca, **José L. Arias-Estero

*Universidad Católica de Murcia (España), **Universidad de Murcia (España)

\begin{abstract}
The aim of this study was to determine the free throw technique and successful free throw technique both prior to ball release and at ball release moments in under-12 basketball, using a court-applied test. The participants were 102 players from eight male under-12 officially federated basketball teams. We used a point/ideographic/multidimensional observational design to analyse the recordings of 612 free throws. The test consisted of performing one, two or three free throws. One participant performed the free throws and the other passed the ball to him. The roles were exchanged until the two participants performed all the free throw options. As a result, the participants did not execute the free throw using the technique proposed by the literature. This difference was because jumping free throws shoots, with low style, feet at the same distance, and moderate forward displacement of the centre of mass predominated. The free throw technique was in general more regular than that of the successful free throws. Players used an unregulated technique, without meeting the criteria that activate success in the free throw. This technique resulted attempting successful free throws at $4 \mathrm{~m}$ from the basket, which is $2.60 \mathrm{~m}$ high, with a 485-g ball. Taking into account the characteristics of the participants of the present work in terms of age, strength, maturity, height, weight, and body mass index, coaches and the competition managers should assess what should be improved in under-12 basketball to allow players to increase free throw success.
\end{abstract}

Keywords: basketball, youth basketball, sport pedagogy, T-pattern.

Resumen: El objetivo de este estudio fue determinar la técnica de tiro libre y la técnica de tiro libre con éxito, tanto antes de la salida del balón como en el momento de salida del balón en baloncesto U-12, a través de un test de tiro. Los participantes fueron 102 jugadores de ocho equipos masculinos de baloncesto U-12 federados. Se utilizó un diseño observacional puntual/ ideográfico/multidimensional para analizar las grabaciones de 612 tiros libres. La prueba consistía en realizar uno, dos o tres tiros libres. Un participante realizaba los tiros libres y el otro le pasaba el balón. Los participantes intercambiaban los roles hasta que los dos realizaron todas las opciones de tiro libre. Los resultados mostraron que los participantes no ejecutaron el tiro libre utilizando la técnica propuesta por la literatura. Esta diferencia se debió a que predominaron los tiros libres con salto, con estilo bajo, pies a la misma distancia y desplazamiento moderado del centro de masas hacia adelante. La técnica de los tiros libres en general fue más regular que la de los tiros libres con éxito. En conclusión, los jugadores utilizaron una técnica alejada de las recomendaciones teóricas, poco regular, y sin cumplir los criterios que posibilitan éxito en el tiro libre. Esto ocurrió como consecuencia de intentar obtener éxito en una situación de tiro libre a $4 \mathrm{~m}$ de la canasta, situada a 2.60 m de altura, y con un balón de 485 g. Teniendo en cuenta las características de los participantes del presente trabajo en cuanto a edad, fuerza, madurez, altura, peso e índice de masa corporal, los entrenadores y los responsables de las competiciones deberían valorar qué debe mejorarse en el baloncesto U-12 para que los jugadores puedan aumentar el éxito en los tiros libres.

Palabras clave: baloncesto, baloncesto juvenil, pedagogía del deporte, patrón temporal.

\section{Introduction}

Many children decide to play basketball because it is one of the most practiced team sports around the world (DiFiori, et al., 2018). The main reason to play basketball is to have fun (DiFiori, et al., 2018), whereas the young players report more fun when they achieve

Fecha recepción: 15-06-21. Fecha de aceptación: 11-09-21

Álvaro Díaz-Aroca

adiaz@ucam.edu more successful shots (Piñar, et al., 2007). However, the lack of shooting success is a common problem in under-12 basketball (Arias, 2012b). Consequently, it seems necessary to investigate the free throw technique and its relation with success in under-12 basketball to identify possible errors. Such mistakes could be causing children to play basketball in an inappropriate practice environment and therefore, to lose interest in being physically active (Miller \& Siegel, 2017).

Shooting is the most decisive game action during a basketball match due to its direct relationship with the 
final result. The free throw, as it is not hindered by the interference of an opponent, has been studied extensively in basketball, from psychological, physiological, and technical perspectives (e.g., Chen, et al., 2018; Maglott, et al., 2019; Przednowek, et al., 2018). Data from the literature suggest that release height, velocity, and angle are main factors related to a successful free throw (e.g., Tran \& Silverberg, 2008). Furthermore, researchers identified prior to ball release and at ball release as the two key moments of free throw study (e.g., de Oliveira, et al., 2008; Okubo \& Hubbard, 2015). Echoing these biomechanical variables, several basketball manuals recommended the ideal free throw technique (e.g., American Sport Education Program [ASEP], 1996). Prior to ball release, the free throw should be executed without jumping, with high style, shooting with one hand and using the other as a supporting hand, feet pointed towards the basket, with same-side foot of the shooting hand placed forward. At ball release, the shooting hand should be oriented towards the basket, with the elbow extended and the arm very close to the vertical, the wrist bent, and the ball should release at the point of maximum height of the centre of mass with no shoulder rotation, and no horizontal displacement of the centre of mass.

Unlike basketball, in under-12 basketball, the number of studies that analysed the free throw is limited. Four of these studies demonstrated the positive effects of reducing the size of the ball and the height of the basket used in adult basketball on free success (Chase, et al., 1994; Regimbal, et al., 1992), technique (Regimbal, et al., 1992; Satern, et al., 1989), and self-efficacy (Chase, et al., 1994). Arias (2012a) found that a ball of lower mass than that used in official competition by under-12 players did not increase free throw accuracy and success. Finally, temporal patterns analysis (T-patterns) was used in the free throw study to demonstrate the absence of prior gestural routines (Lapresa, et al., 2011) and that the regulatory change from the under- 12 to the under14 category led to a worse technique and decreased success (Garzón, et al., 2014).

The use of the T-patterns to analyse the free throw technique in under-12 basketball was a turning point because it led to the discovery of hidden behaviours. Briefly, based on a powerful algorithm, T-patterns search for relationships between events (free throw in the present work) by simultaneously taking into account order, relative and real timing and frequency of these events, as well as their hierarchical structure (e.g., Casarrubea, et al., 2018). These sequences of behaviours are «hidden among many other events and therefore difficult to see at a first look» (Magnusson, et al., 2004, p. 167). Another powerful statistical technique is polar coordinate analysis (Sackett, 1980), recently used to sport analysis (e.g., Pérez-Tejera, et al., 2019). This technique allows data reduction based on the Zsum statistic in a vectorial representation to show the relationship between a given criterion (or focal criterion) and one or more conditional criteria. These relationships are significant $(p<.05)$ when the vector length is $>1.96$ (excitatory). Hence, the relationship between the focal and the conditional criteria in the quadrant I indicates mutual prospective and retrospective activation (i.e., the two criteria activate each other in both directions; Gorospe \& Anguera, 2000).

In short, the importance of free throw technique in basketball has been previously highlighted. However, only Garzón et al. (2014) analysed the free throw technique in under-12 basketball. Nevertheless, none of the previous studies investigated this technique differentiating between prior to ball release and at ball release in relation with success and using T-patterns and polar coordinate statistical techniques. Building on these limitations the aim of this work was to determine the free throw technique and successful free throw technique both prior to ball release and at ball release in under-12 basketball, using a court-applied free throw test. The first hypothesis was that the participants would not execute the free throw using the technique proposed by the literature. The second was that the successful free throw technique would be similar to the one proposed in the literature. The third was that the successful free throw technique would be more regular than that of free throws in general.

\section{Method}

\section{Participants}

The participants were 102 players $\left(\mathrm{M}_{\text {age }}=10.67\right.$ years, $\mathrm{SD}=.43$ years, age range $=9-11$ years $)$, from eight male under-12 officially federated basketball teams that played regionally. Participants trained a mean of $3.52(S D=.48)$ days, during a mean of $4.15 \mathrm{hr}$ per week $(S D=.60)$ and played competitive matches at least once a week. None of them was injured during the study. All the teams that competed in the first division at regional level were participants for three reasons. First, they accepted: (a) participating in all scheduled tests, and (b) being recorded during each test. Second, they competed in the top regional level. Third, they 
had homogeneous features related to previous basketball experience $(M=3.35, S D=.30$ years, $p>.05)$, strength level $(M=20.38, S D=1.18 \mathrm{Nw}, p>.05)$, maturity offset $(M=-1.25, S D=.33, p>.05)$, height $(M=1.40, S D=.19 \mathrm{~m}, p>.05)$, weight $(M=39.5, S D$ $=9.89 \mathrm{Kg}, p>.05)$ and body mass index $(M=19.7, S D$ $\left.=3.25 \mathrm{~kg} / \mathrm{m}^{2}, p>.05\right)$. Participants' parents completed informed consent forms, and participants provided their assent. The University's Research Ethics Committee approved the study and it was performed according to the Helsinki Declaration.

\section{Design}

We used a point / ideographic / multidimensional observational design (Anguera \& Izquierdo, 2006). The design was point because the participants were tested midway through the season in the month of February. Each day, the test was performed by one team, so all the teams were tested in the two-week period. The design was ideographic because the 612 free throws performed by the players, who were analysed as a group, were observed. Finally, the design was multidimensional, because the criteria analysed were differentiated according to prior to ball release and at ball release (Figure 1). These criteria were determined by deductive strategies (including all criteria and categories obtained after a thorough theoretical review of the technique of free throw) and inductive (including all the criteria and category possibilities after observing 2240 free throws of the studied population). In addition, the success of each free throw, understood as a result of scoring or not scoring a basket, was recorded.

\section{Procedure}

Researchers tested each team individually during a training session from 18:00 to 19:30 hours and at a similar environmental temperature (i.e., $19.1-22.3^{\circ} \mathrm{C}$ ). Each team was assigned to a test day by simple randomization. The second author generated the random allocation sequence through a computer-generated algorithm, and the first author assigned the teams. The researchers attended each team's usual play court and prepared the set up in which the test was conducted. That was, a free throw $4 \mathrm{~m}$ from the basket, located $2.60 \mathrm{~m}$ high, and with a ball of $485 \mathrm{~g}$. Two cameras were used (Everio Full HD-GZ-GX1BE, JVC, Japan), at a height of $1.30 \mathrm{~m}$ and $5 \mathrm{~m}$ from the player. One was placed sideways and parallel to the player in the free throw position, to record the player, the trajectory of the ball and the basket. The other camera was placed under the basket in order to record the player head-on, as well as the ball release trajectory. This test was previously piloted to verify that there was no influence due to the order of execution of the free throw options or the moment when participants executed the free throw (Author). Coaches were asked not to train any differently than usual. They stated that players usually practiced the free throw and received feedback from the coaches for approximately 10 minutes in each training session ( $9 \%$ of the total training time).

All the teams performed the same pre-test exercises. First, a general warm-up, consisting of joint mobility (5 minutes), stretching ( 5 minutes), and dribbling while running (3 minutes). Second, a task of handling the ball while dribbling ( 5 minutes) and another

\begin{tabular}{|c|c|c|c|}
\hline Criteria & Category & Criteria & Category \\
\hline \multirow{2}{*}{ Type of shot } & - Without jumping. & \multirow{3}{*}{ Ball release moment } & - Point of maximum height of the centre of mass. \\
\hline & - Jumping. & & - Before the point of maximum height of the centre of mass. \\
\hline \multirow{2}{*}{ Shooting style } & - High. & & - After the point of maximum height of the centre of mass. \\
\hline & - Low. & \multirow{4}{*}{ Placement of the support hand } & - Lateral and static. \\
\hline \multirow{2}{*}{ Shooting hand } & $\begin{array}{l}\text { - One hand (only the right or left hand provide force to direct the ball toward the } \\
\text { basket and there is support hand). }\end{array}$ & & - Moves down. \\
\hline & $\begin{array}{l}\text { - Both hands (both hands provide force to direct the ball toward the basket and } \\
\text { there is not support hand). }\end{array}$ & & - Moves up. \\
\hline \multirow{3}{*}{ Placement of the shooting hand } & $\begin{array}{l}\text { - Below the ball. } \\
\text { - On the side of ball. }\end{array}$ & & $\begin{array}{l}\text { - Separates laterally. } \\
\text { - No support hand. }\end{array}$ \\
\hline & $\begin{array}{l}\text { - Below and on the side of ball. } \\
\text { - Both hands behind the ball. }\end{array}$ & Shooting hand height & $\begin{array}{l}\text { - Upper line. } \\
\text { - Under line. }\end{array}$ \\
\hline & - Both hands on the side of ball. & \multirow{2}{*}{ Orientation of the shooting hand } & -Towards the basket. \\
\hline \multirow{4}{*}{ Placement of the support hand } & - No support hand. & & - Inward. \\
\hline & - On the side of ball. & \multirow{3}{*}{ Extension of the shooting elbow } & - Fully extended $\left(180^{\circ}\right)$ \\
\hline & $\begin{array}{l}\text { - Below the ball. } \\
\text { - Behind the ball. }\end{array}$ & & $\begin{array}{l}\text { - Not very extended }\left(<180^{\circ} \text { and }>90^{\circ}\right) \text {. } \\
\text { - Very bent }\left(<90^{\circ}\right) \text {. }\end{array}$ \\
\hline & - Above the ball. & & - Very close to the vertical $\left(<45^{\circ}\right)$. \\
\hline Bending the shooting elbow & $\begin{array}{l}\text { - Very bent }\left(<90^{\circ}\right) \text {. } \\
\text { - Medium bent }\left(\text { close to } 90^{\circ}\right) \text {. }\end{array}$ & Verticality of the shooting arm & $\begin{array}{l}\text { - Close to the vertical }\left(\text { close to } 45^{\circ}\right) \text {. } \\
\text { - Not close to the vertical }\left(>45^{\circ}\right) \text {. }\end{array}$ \\
\hline Height of the centre of mass & $\begin{array}{l}\text { - High (toes lift off the ground }>10 \mathrm{~cm} \text { ). } \\
\text { - Low (toes lift off the ground }<10 \mathrm{~cm} \text { ). } \\
\text { - Without jumping. }\end{array}$ & Bending shooting wrist & $\begin{array}{l}\text { - Fully bent. } \\
\text { - Incompletely bent. } \\
\text { - Long forward (distance }>\text { half a foot). }\end{array}$ \\
\hline Feet angle & $\begin{array}{l}\text { - Both feet point towards the basket. } \\
\text { - Only same-side foot as the shooting hand points toward the basket. } \\
\text { - No foot points toward basket. }\end{array}$ & \multirow[t]{2}{*}{$\begin{array}{l}\text { Horizontal displacement of } \\
\text { centre of mass }\end{array}$} & $\begin{array}{l}\text { - Moderate forward (distance }<\text { half a foot). } \\
\text { - Long backward (distance }>\text { half a foot). } \\
\text { - Moderate backward (distance }<\text { half a foot). }\end{array}$ \\
\hline \multirow[b]{2}{*}{ Placement of feet } & - At same distance & & - No displacement. \\
\hline & $\begin{array}{l}\text { - Same-side foot of shooting hand placed forward. } \\
\text { - Opposite foot of shooting hand placed forward. }\end{array}$ & \multirow{2}{*}{ Shoulder rotation } & $\begin{array}{l}\text { - No rotation. } \\
\text { - To the right. }\end{array}$ \\
\hline Bending knees & $\begin{array}{l}\text { - Small }\left(>120^{\circ}\right) \\
\text { - Medium }\left(<120^{\circ}\right)\end{array}$ & & - To the left. \\
\hline
\end{tabular}


of lay-ups ( 5 minutes). After the shooting task, the participants began to perform the test. The rest of the participants continued to perform dribbling tasks and alternating shots at low intensity to avoid fatigue. Participants did not practice the free throw prior to the test. Players took less than 15 minutes to take the test and, in total, each team took less than 90 minutes to take the test.

The test consisted of performing one, two or three free throws, to resemble what occurs in a real game. The performance was in pairs, so that one participant performed the free throws and the other passed the ball to him. By means simple randomization, as instructed by the principal investigator, each participant shot one, two or three free throws. After each of the previous options of free throw, the roles were exchanged until both participants performed all the free throw options. No player shot more than three free throws in a row. Once the participant had the ball, he had 5 seconds to shoot, as indicated by the regulations. Participants were asked to face free throw as they normally do in real matches. When the pair finished performing the test, another pair would start it. The order of participation of the participants was also by simple randomization. The second author generated the random allocation sequence through a computer-generated algorithm, and the first author assigned the order of participation.

The videos of the free throws were observed by two observers with more than ten years of coaching experience in under- 12 basketball and more than 900 hours of experience in observing game actions in under12 basketball. They were trained for 30 hours for the observation of the specific criteria of this study. The reliability of observers at the end of the training was calculated (intraclass correlation coefficient $>.98$, and percentage of agreement $>93 \%$ ).

The observers used a systematized register to record data from the videos, using a recording instrument from the adaptation of a Microsoft Excel 2003 (Microsoft Corporation, USA) spreadsheet, along with a programme to capture and process the videos (VirtualDub, v. 1.10.4). This technique consisted of registering, in each cell of the register instrument, the category met from each criterion for each participant's free throw. Observers observed each free throw individually. Each observer observed a maximum of 60 free throws at each observation session to avoid the effect of fatigue. They started each session by reobserving all 30 free throws of the previous session to detect possible errors and then, observed 30 new free throws. The observers viewed each free throw three times at real speed. If necessary, they observed each free throw at a speed of 25 frames/s. They observed the videos of the free throws recorded laterally and from the front of the participant. Observers took 31 hours over six weeks to observe the 612 free throws executed by the participants. Both observers observed all the free throws. Hence, they discussed disagreements up to reach an agreement.

\section{Data analysis}

First, the Theme v6 EDU software was used to perform the analysis that enabled the detection of $\mathrm{T}$ patterns of the free throw in general and the successful free throws. The search parameters were the following: (a) minimum number of occurrences set at 3 (percentile $>80 \%$ ), (b) reduction of redundancies set at $90 \%$, (c) without coincidences between real T-patterns and those randomized five times, and (d) significance level at $p<$ .005. We only accepted the T-pattern with internal intervals smaller than those of the tested relationship $(\mathrm{n} / 2000,<.005)$. Second, to establish the relationship presented between the technical criteria and the success criterion, the HOISAN 1.6 software was used, and the polar coordinate technique was implemented (Sackett, 1980). The success criterion was defined as focal, whereas each of the technical criteria of the free throw was established as conditional. This study considered transitions greater than or equal to 1.96 from quadrant I, if significant $(p<.05)$, to represent a greater probability than that expected if left to chance (Gorospe \& Anguera, 2000). The SDIS-GSEQ (Bakeman \& Quera, 1996) programme was used prior to the polar coordinate analysis to verify the sequential analysis of the data. We also checked whether the results were inûuenced by the effect of: (a) the randomness of the free throw options' order (one, two or three), (b) the randomness of participants' free throw moments (start or end of each session) and (c) the different teams. This checking was done in each of the above-mentioned analyses, so that the former tests were used, respectively. All the previous analyses were carried out differentiating the criteria prior to ball release and at ball release.

\section{Results}

\section{Prior to ball release}

The results showed 44 different T-patterns prior to ball release (Table 1). Both the mean frequency of multi- 
events and of the T-pattern was higher in the free throws in general than in the successful ones (Table 1). This difference indicated that the technique of successful free throws was less regular than that of the free throws in general. The most repeated T-pattern (116 times) showed a low-style free throw, using one hand, placed below the ball and the supporting hand on the side of the ball, medium bending of the shooting elbow, low height of centre of mass, small bending of knees, feet placed at the same distance and pointed towards the basket (Figure 2A above). The second most repeated Tpattern varied from the first in a greater bending of the shooting elbow (Figure 2B above). The most repeated T-pattern coincided with the most frequently successful T-pattern (Figure 2A below). The next most successful detected T-pattern varied from the previous one in that it was executed with high style and without jumping (Figure 2B below). Polar coordinate analysis found that these criteria, together with the very bent shooting elbow, were the ones that activated success (Table 2). Specifically, the high shooting style, with a very bent shooting elbow and without jumping, were the most activating criteria of success (radius $=4.31,2.89,2.17$, respectively).

Table 1

Number, types and mean frequency of free throw multi-events and T-patterns prior to ball release and at ball release, in general and in successful free throws

\begin{tabular}{lcccccc}
\hline \multicolumn{3}{c}{ and at ball release, in general and in successful free throws } \\
\hline & $n$ & $n$ & Mean & $n$ & $n$ & $\begin{array}{c}\text { Mean } \\
\text { (types) }\end{array}$ \\
& (total) & frequency & (types) & (total) & frequency \\
\hline Free throws prior to ball release & 66 & 612 & 9.27 & 44 & 474 & 10.77 \\
Free throws at ball release & 150 & 612 & 4.08 & 41 & 319 & 7.78 \\
Successul free throws prior to ball release & 48 & 216 & 4.5 & 12 & 97 & 8.08 \\
Successful free throws at ball release & 78 & 216 & 2.76 & 10 & 62 & 6.2 \\
\hline
\end{tabular}

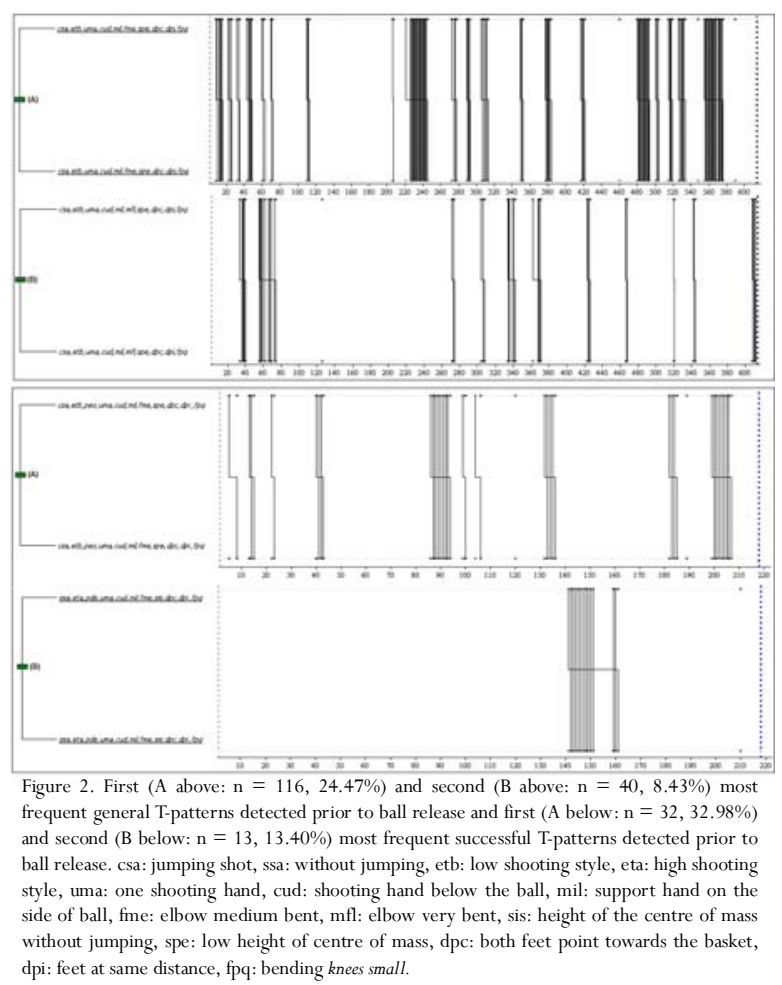

Table 2

Polar coordinate analysis results for the relationship between the focal category (success) and criteria in prior to ball release and at ball release

\begin{tabular}{|c|c|c|c|c|c|c|}
\hline Category & Quadrant & $\begin{array}{c}\text { Prospective } \\
\text { Zsum }\end{array}$ & $\begin{array}{c}\text { Retrospective } \\
\text { Zsum }\end{array}$ & Ratio & Radius & Angle \\
\hline \multicolumn{7}{|l|}{ Prior to ball release } \\
\hline Without jumping & I & .89 & 1.98 & .91 & $2.17(*)$ & 65.69 \\
\hline Jumping & III & -.89 & -1.98 & -.91 & $2.17(*)$ & 245.69 \\
\hline High style & I & 4.05 & 1.5 & .35 & $4.31(*)$ & 20.35 \\
\hline Low style & III & -4.05 & -1.5 & -.35 & $4.31(*)$ & 200.35 \\
\hline One shooting hand & III & -1.25 & -.3 & -.23 & 1.29 & 193.38 \\
\hline Both shooting hands & I & 1.25 & .3 & .23 & 1.29 & 13.38 \\
\hline Below the ball & II & -.15 & 1.02 & .99 & 1.03 & 98.12 \\
\hline On the side of ball & III & -1.37 & -1.69 & -.78 & $2.18(*)$ & 231.08 \\
\hline Below and on the side of ball & IV & 1.88 & -.29 & -.15 & 1.9 & 351.28 \\
\hline Both hands behind the ball & II & -.3 & .21 & .58 & .37 & 144.54 \\
\hline Both hands on the side of ball & III & -.37 & -.42 & -.75 & .56 & 228.28 \\
\hline No support hand & I & 1.25 & .3 & .23 & 1.29 & 13.38 \\
\hline On the side of ball & II & -3.86 & .91 & .23 & $3.96(*)$ & ) 166.74 \\
\hline Below the ball & III & -1.07 & -1.99 & -.88 & $2.26(*)$ & ) 241.78 \\
\hline Behind the ball & IV & 5.5 & -1.14 & -.2 & $5.62(*)$ & 348.29 \\
\hline Above the ball & I & 1.53 & .09 & .06 & 1.54 & 3.3 \\
\hline Elbow very bent $\left(<90^{\circ}\right)$ & I & 1.14 & 2.65 & .92 & $2.89(*)$ & 66.7 \\
\hline Elbow medium bent (close to $90^{\circ}$ ) & III & -1.14 & -2.65 & -.92 & $2.89(*)$ & ) 246.7 \\
\hline High (toes lift off the ground $>10 \mathrm{~cm}$ ) & II & -.29 & .65 & .91 & .71 & 114.24 \\
\hline Low (toes lift off the ground $<10 \mathrm{~cm}$ ) & III & -.38 & -1.94 & -.98 & $1.97(*)$ & ) 258.95 \\
\hline Without jumping & I & .89 & 1.98 & .91 & $2.17(*)$ & ) 65.69 \\
\hline Both feet point towards the basket & IV & 2.2 & -.28 & -.13 & $2.22(*)$ & 352.66 \\
\hline $\begin{array}{l}\text { Only same-side foot as the shooting } \\
\text { hand points toward the basket }\end{array}$ & III & -2.26 & -.6 & -0.25 & $2.34(*)$ & 194.76 \\
\hline No foot points toward basket & II & -.58 & 1.16 & 0.9 & 1.3 & 116.48 \\
\hline Feet at same distance & II & -.03 & .34 & 1 & 0.34 & 94.84 \\
\hline $\begin{array}{l}\text { Same-side foot of shooting hand placed } \\
\text { forward }\end{array}$ & III & -.25 & -.06 & -0.21 & 0.26 & 192.34 \\
\hline $\begin{array}{l}\text { Opposite foot of shooting hand placed } \\
\text { forward }\end{array}$ & IV & 2.31 & -2.34 & -0.71 & $3.29(*)$ & ) 314.61 \\
\hline Bending knees small $\left(>120^{\circ}\right)$ & II & -.04 & .53 & .89 & .86 & 99.83 \\
\hline $\begin{array}{l}\text { Bending knees medium }\left(<120^{\circ}\right) \\
\text { At ball release }\end{array}$ & IV & 2.98 & -.67 & -.21 & 1.2 & 326.21 \\
\hline $\begin{array}{l}\text { Point of maximum height of the centre } \\
\text { of mass }\end{array}$ & I & 2.32 & .37 & .16 & $2.35(*)$ & 9.01 \\
\hline $\begin{array}{l}\text { Before the point of maximum height of } \\
\text { the centre of mass }\end{array}$ & III & -2.63 & -.21 & -.08 & $2.64(*)$ & ) 184.57 \\
\hline $\begin{array}{l}\text { After the point of maximum height of } \\
\text { the centre of mass }\end{array}$ & IV & 1.86 & -.97 & -.46 & $2.1(*)$ & 332.44 \\
\hline Support hand lateral static & I & .09 & 2.91 & 1 & $2.91(*)$ & ) 88.22 \\
\hline Support hand moves down & III & -.66 & -3.8 & -.99 & $3.86(*)$ & 260.16 \\
\hline Support hand moves up & IV & .23 & -.72 & -.95 & .75 & 287.48 \\
\hline Support hand separates laterally & II & -2.56 & .39 & .15 & $2.59(*)$ & ) 171.28 \\
\hline No support hand & I & 1.84 & .28 & .15 & 1.86 & 8.61 \\
\hline Upper line & III & -1.79 & -.1 & -.06 & 1.8 & 183.34 \\
\hline Under line & I & 1.79 & .1 & .06 & 1.8 & 3.34 \\
\hline $\begin{array}{l}\text { Orientation shooting hand towards the } \\
\text { basket }\end{array}$ & II & -.04 & .83 & 1 & .83 & 92.7 \\
\hline Orientation shooting hand inward & IV & .04 & -.83 & -1 & .83 & 272.7 \\
\hline Elbow fully extended $\left(180^{\circ}\right)$ & I & 3.63 & 4.54 & .78 & $5.82(*)$ & ) 51.37 \\
\hline $\begin{array}{l}\text { Elbow not very extended }\left(<180^{\circ} \text { and }\right. \\
\left.>90^{\circ}\right)\end{array}$ & III & -3.86 & -4.66 & -.77 & $6.05(*)$ & 230.38 \\
\hline Elbow very bent $\left(<90^{\circ}\right)$ & I & .98 & .31 & .3 & 1.03 & 17.35 \\
\hline Very close to the vertical $\left(<45^{\circ}\right)$ & I & 3.72 & 2.76 & .6 & $4.63(*)$ & ) 36.63 \\
\hline Close to the vertical (close to $45^{\circ}$ ) & III & -2.79 & -2.04 & -.59 & $3.45(*)$ & ) 216.18 \\
\hline Not close to the vertical $\left(>45^{\circ}\right)$ & III & -.38 & -0.33 & -.66 & .5 & 220.98 \\
\hline Wrist fully bent & I & 1.95 & 6.05 & .95 & $6.36(*)$ & ) 72.17 \\
\hline Wrist incompletely bent & III & -1.95 & -6.05 & -.95 & $6.36(*)$ & ) 252.17 \\
\hline Long forward (distance $>$ half a foot) & II & -2.67 & 1.98 & .59 & $3.33(*)$ & 143.53 \\
\hline $\begin{array}{l}\text { Moderate forward (distance }<\text { half a } \\
\text { foot) }\end{array}$ & IV & 2.58 & -.5 & -.19 & $2.63(*)$ & ) 349.07 \\
\hline Long backward (distance $>$ half a foot) & IV & 1.31 & -.13 & -.1 & 1.32 & 354.17 \\
\hline $\begin{array}{l}\text { Moderate backward (distance }<\text { half a } \\
\text { foot) }\end{array}$ & III & -2.86 & -3.56 & -.78 & $4.57(*)$ & ) 231.26 \\
\hline No displacement & I & .47 & 1.01 & .91 & 1.11 & 65.19 \\
\hline No rotation & I & 2.37 & 1.11 & .43 & $2.62(*)$ & ) 25.16 \\
\hline To the right & III & -1.95 & -1.14 & -.5 & $2.26(*)$ & ) 210.29 \\
\hline To the left & III & -1.58 & -.63 & -.37 & 1.7 & 201.74 \\
\hline
\end{tabular}

\section{At ball release}

The results showed 41 different T-patterns at ball release (Table 1 ). Both the mean frequency of multievents and of the T-pattern were higher in the free throws in general than in the successful ones (Table 1). This difference indicated that the successful free throw technique was less regular than that of the free throws in general. The most repeated T-pattern (48 times) showed the following criteria: the ball released the player's hands at the maximum height point of the cen- 
tre of mass, upper line, fully extended shooting elbow, shooting arm close to the vertical and oriented towards basket, full wrist bending, supporting hand lateral and static, and moderate forward horizontal displacement of centre of mass, without shoulder rotation (Figure 3A above). The next most frequent T-pattern varied from the first one in that the ball released before the maximum height point of the centre of mass (Figure 3B above). On the contrary, the most frequently successfulT-pattern varied from the most frequent T-pattern in that the shooting arm was very close to the vertical and there was no horizontal displacement of centre of mass (Figure $3 \mathrm{~A}$ below). However, the second most frequently successful T-pattern was the same as the second most frequent T-pattern (Figure 3B below). The polar coordinate analysis coincided in detecting the shooting arm criterion very close to the vertical as a activator of success, but also identified the fully extended shooting elbow, full wrist bending, lateral and static supporting hand and no rotation of shoulders (Table 2). Specifically, full wrist bending, fully extended shooting elbow, arm very close to the vertical, lateral and static supporting hand, no shoulder rotation, and at the point of maximum height of the centre of mass were the criteria that activated success (radius $=6.36,5.82,4.63,2.91,2.62$, 2.35, respectively).

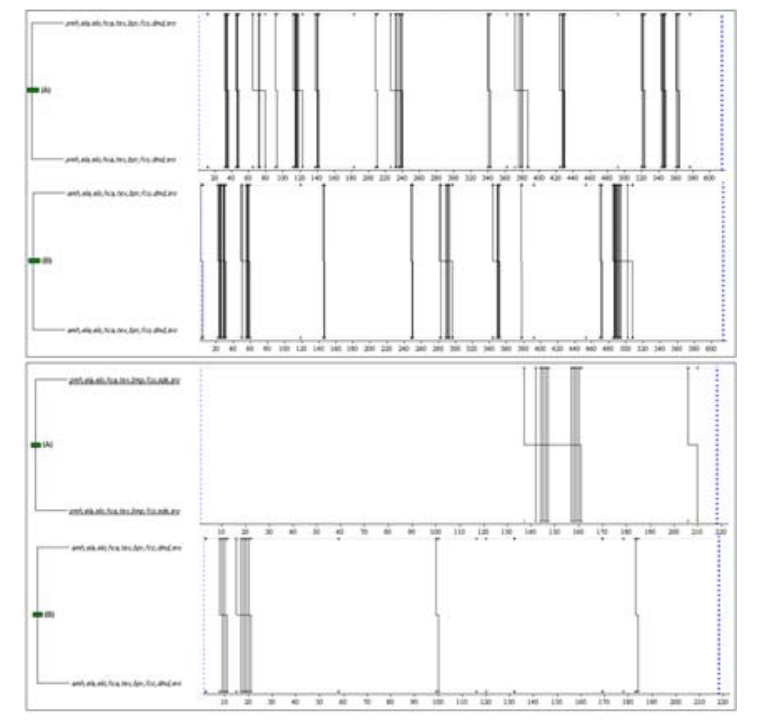

Figure 3. First ( $\mathrm{A}$ above: $\mathrm{n}=48,15.04 \%$ ) and second (B above: $\mathrm{n}=42,13.16 \%$ ) most frequent general T-patterns detected at ball release and first (A below: $\mathrm{n}=11,17.74 \%$ ) and second (B below: $\mathrm{n}=8,12.90 \%$ ) most frequent successful T-patterns detected at ball release. pmh: point of maximum height of the centre of mass, amh: before the point of maximum height of the centre of mass, ela: support hand lateral and static, elo: shooting hand upper line, hca: orientation of the shooting hand towards the basket, tex: elbow fully extended, bmp: shooting hand very close to the vertical, bpr: shooting hand close to the vertical, fco: wrist fully bent, sde: without horizontal displacement of centre of mass, dmd: moderate forward displacement of centre of mass, sro: without shoulder rotation.

\section{Quality of data}

The results showed differences when we checked whether they were inûuenced by the effect of the different teams $(p<.05)$. No differences were observed when the randomization effect of the free throw options' order, and participants' moments were checked.

\section{Discussion and conclusion}

The aim of the present work was to determine the free throw technique and successful free throw technique both prior to ball release and at ball release in under-12 basketball. The results ratified the first hypothesis because the participants did not execute the free throw using the technique proposed by the literature. This difference happened because the low style free throws, with jumping, feet placed at the same distance, and moderate forward displacement of the centre of mass predominated with respect to the technique proposed by the literature (ASEP, 1996). However, the results did not totally ratify the second hypothesis because the technique of successful free throws was not equal to that proposed in the literature for prior to ball release (ASEP, 1996). This variation was because the most frequent T-pattern prior to ball release coincided with the most frequent successful one at that same moment (Figure 2). In general, there could be two reasons for the results with respect to the first and second hypotheses. First, everything indicates that the conditions of free throw were not adequate to the physical characteristics of the participants, as well reported Garzón et al. (2014). This finding was supported by the suggestion that shorter players have a greater need for the energy of a counter-movement around the elbow and wrist joints (Okazaki, et al., 2015). That was why the participants had to adopt a different technique than the ideal prior to ball release compared to what happened at ball release, in order to generate the necessary force to achieve success (Chen, et al., 2018). Second, in relation to the previous reason, the coaches allow players to make adaptations to their technique of free throw to score a basket (Ammar, et al., 2016; Arias, 2012b; Garzón, et al., 2014). That is, they give priority to immediate success rather than to the training of the players (Lefebvre, et al., in press). However, Ammar et al. (2016) asserted that to be more successful in the free throw, players in their first stage of technique learning should work to improve the technique.

The results did not confirm the third hypothesis because the free throw technique in general was more regular than that of the successful free throws. This detection highlighted that the participants used different compensatory strategies, not synchronously regular 
ones, to score a basket, by re-organising the coordination of the body segments to meet the demands of the free throw (Mullineaux \& Uhl, 2010). This difference between the general technique and the successful technique was reinforced because the criteria observed in the free throw pattern with which players achieved success (Figures 2 and 3 below) did not coincide with the results obtained in the polar coordinate analysis (Table 2). Furthermore, the irregularity was lower prior to ball release than at ball release (in general and in the successful free throws), which, in accordance with Tpattern results (Figure 2) means that the participants had assimilated a different technique from that recommended by the literature prior to ball release. So that, as in Mullineaux and Uhl's work (2010), a little irregularity in patterns prior to ball release may have been disadvantageous to achieve more regularity in ball release patterns. In accordance, researchers caution that increases in force or velocity generation may reduce the players' success because both are related to movement irregularity (Urbán, et al., 2019). However, the free throw is a special component based on automatic movements, always performed in the same way with a suitable rhythm and speed (Przednowek, et al., 2018). Based on the results of the analysis by polar coordinate, the criteria associated with success corresponded with those reported by the literature (ASEP, 1996): no jump, high style, shooting elbow very bent prior to ball release, ball release at the point of maximum height of the centre of mass, lateral and static supporting hand, fully extended shooting elbow, shooting arm very close to the vertical at ball release, full wrist bending and no shoulder rotation.

Garzón et al. (2014) also found that performing the free throw without jumping increased success because the stability is greater. Stability was also favoured by performing the free throw without shoulder rotation. This stability makes possible to increase accuracy (Tran \& Silverberg, 2008). Okazaki et al. (2015) showed that an excessive increase in the horizontal displacement of the centre of mass, decreased the accuracy of the free throw, as in the present study. Furthermore, poor shooters showed significantly higher horizontal displacement of centre of mass compared to good shooters (Verhoeven \& Newell, 2016). The participants in this study, in addition, placed the supporting hand static and to the side so as not to interfere with ball release (Gómez, et al., 2017). Therefore, movement stability and postural control are essential features for shooting accuracy (Palmer, et al., 2018). However, some players may shoot without stability as a strategy to capitalise on the potential energy created both by the elbow extensor muscles and pre-stretching the wrist flexors, as the present work reported (Figures 2 and 3 below). These strategies generate greater force and speed that can be applied to the ball at release, thereby decreasing the muscle effort needed to release the ball for a successful shot (Okazaki, et al., 2015).

As in the study of Arias (2012b), the high-throw style was a technical criterion activator of success. This result could have been due to two factors. First, the high style allows players to look at the basket from under the ball during the final sequence of the shot (de Oliveira, et al., 2008). If players cannot look at the basket during the entire final throwing phase or immediately before ball release, they cannot make adjustments during this phase (de Oliveira, et al., 2008). Second, the high style allows the increase of the angle and height of ball release (Tran \& Silverberg, 2008). In this regard and as previous studies reported, the two key criteria that activated success were releasing the ball at the point of maximum height of the centre of mass together with the shooting arm very close to the vertical (Oudejans, et al., 2012). Increasing the angle and height of ball release leads to a decrease of release speed. A throw with these characteristics is more likely to be more accurate (Tran \& Silverberg, 2008). However, as occurred in the present work (Figure 2), when free throwing, it is common for young players that the ball releases before the point of maximum height of the centre of mass and with a low style in order to generate higher force and at least allow the ball to touch the rim (Arias, 2012b; Garzón, et al., 2014). That is why the very bent shooting elbow criterion prior to ball release also activated success, as it helped the young players to generate higher force at ball release (Okubo \& Hubbard, 2015), reducing the difficulties associated with lack of muscle power (GarcíaChaves, et al., 2021).

In relation to the above biomechanical factors, the theoretical literature recommends that the shooting elbow be fully extended at ball release (ASEP, 1996), as in this work (Table 2). This measure contributes to increase the high of ball release, transfer the force from the lower-body to the upper-body following the kinetic chain, and promote the bending of the wrist (Okazaki, et al., 2015). As a consequence, full wrist bending was a key to activate success (Table 2), as Okubo and Hubbard (2015) also found. This full wrist bending is relevant for two reasons (Okubo \& Hubbard, 2015). First, full wrist bending contributes to increase the ball release velocity. 
Second, it allows the backspin, which tends to redirect the ball towards the centre of the basket after any left or right error with a bounce on the far rim.

In general, the variables that influenced performance of the free throw included players' physical characteristics to achieve higher ball release height and angle, as well as players' ability to generate force, stability, and backspin. To use this information in a coaching or teaching context, it appears that players could try to throw without jumping, using a high style, with the shooting elbow very bent prior to ball release, lateral and static supporting hand, fully extended shooting elbow, arm very close to the vertical at ball release, full bending of the wrist and no rotation of shoulders, so that the ball releases the player's hands at the maximum height of the centre of mass. The identification of these key components related to success in free throw is necessary for the development of proper feedback training and learning technique in beginner basketball players (Ammar, et al., 2016). It is important that they learn to execute a correct free throw as children because habits acquired during motor skills learning at early ages are still present after specific practice has ceased (Memmert, 2006). Gómez, Kreivyte, and Sampaio (2018) suggested that one of the reasons for the low percentages of success in the free throw is that most players never learned the proper technique at an early stage.

In conclusion, players used a technique far removed from the theoretical recommendations, unregulated, and without meeting the criteria that activate success in the free throw. This technique occurred as a result of trying to score a basket in a free throw at $4 \mathrm{~m}$ from the basket, which was $2.60 \mathrm{~m}$ high, and with a $485-\mathrm{g}$ ball. Taking into account the characteristics of the participants of the present work in terms of age, strength, maturity, height, weight, and body mass index, coaches and the competition managers should assess what should be improved in under-12 basketball to allow players to increase free throw success. Different studies have suggested the importance of adapting the ball, basket, and court dimensions to the children's characteristics (e.g., Arias, 2012a; Arias-Estero, et al., 2018). Future studies should check for possible improvements in the free throw technique using scaled equipment.

\section{Acknowledgements}

During the preparation of this manuscript, the first author was supported through the UCAM Research
Vice-Rector's Plan - Predoctoral Contracts Subprogram for the Training of Research Staff [11/11/2017FPI]

\section{References}

Ammar,A., Chtourou,H.,Abdelkarim, O., Parish,A.,Hoekelmann, A. (2016). Free throw shot in basketball: Kinematicanalysis of scored and missed shots during the learning process. Sport Sciences for Health, 12, 27-33. https: / / doi.org/10.1007/ s11332-015-0250-0

Anguera, M.T., \& Izquierdo, C.(2006). Methodologicalapproaches in human communication. From complexity of situation to dataanalysis. In G. Riva, M.T.Anguera, B.K.Wiederhold, \&F. Mantovani(Coord.), From communication to presence. Cognition, emotions and culture towards the ultimate communicative experience (pp. 203-222).Amsterdam, Netherlands: IOSPress.

Arias, J.L. (2012a). Free throw accuracy and success as afunction of ball weight in 9- to 11-year-old male players. Motriz, 18 , 338-344. https://doi.org/10.1590/S198065742012000200014

Arias, J.L.(2012b). Performance as a function of shooting stylein basketball players under 11 years of age. Perceptual and Motor Skills, 114(2), 446-456. https://doi.org/10.2466/ 05.11.PMS.114.2.446-456

Arias-Estero, J.L.,Argudo, F. M., \&Alonso,J. I. (2018). One-onone situationdecision-makingaccording toequipmentin youth basketball. International Journal of Sports Science \& Coaching, 13, 72-77.https://doi.org/10.1177/1747954117746494

ASEP (1996). Coaching youth basketball (2nd ed.). Champaign, IL: Human Kinetics.

Bakeman, R., \& Quera, V. (1996). Interaction analysis. Sequential analysis with SDIS and GSEQ.Madrid:Ra-Ma.

Casarrubea, M., Magnusson, M.,Anguera, M.T., Jonsson, G., Castañer, M., Santangelo, A., . . . Crescimanno, G. (2018).Tpatterndetectionandanalysisfor the discovery of hiddenfeatures of behavior. Journal of Neuroscience Methods,310, 24-32.https: / /doi.org/10.1016/j.jneumeth.2018.06.013

Chase, M.A., Ewing, M. E.,Lirgg, C.D., \& George,T. R. (1994). The effects of equipment modification on children's selfefficacy and basketball shootingperformance. Research Quaterly for Exerciseand Sport, 65, 159-168.https://doi.org/10.1080/ 02701367.1994.10607611

Chen,W.H.,Wu,H.J.,Lo,S.L., Chen,H,Yang,W.W.,Huang, C.F., \& Liu, C. (2018). Eight-week battle rope training improves multiple physical fitness dimensions and shooting accuracy in collegiate basketball players. Journal of Strength and Conditioning Research, 32, 2715-2724. https://doi.org/10.1519/ JSC.0000000000002601

de Oliveira, R., Oudejans, R., \& Beek, P. J. (2008) Gaze behavior in basketball shooting: further evidence for online visual control. Research Quarterly of Exercise and Sports, 79, 399-404. https://doi.org/10.1080/ 
02701367.2008.10599504

di Fiori, J. P., Gü llich, A., Brenner, J. S., Côté, J., Hainline, B., Ryan, E., \& Malina, R. M. (2018).The NBA and youth basketball: Recommendations for promoting a healthy and positive experience. Sports Medicine, 48, 2053-2065. https: / / doi.org/10.1007/s40279-018-0950-0

García-Chaves, D. C., Corredor-Serrano, L.F., \& Arboleda-Franco, S. A. (2021). Relación entre potencia muscular, rendimientofísico y competitivo en jugadores debaloncesto. Retos, 41,191-198.https://doi.org/10.47197/retos.v0i41.82748

Garzón, B. ,Lapresa,A.,Anguera, M.T., \&Arana, J. (2014). From mini-basketball to basketball: The impact of the current regulations on the technical execution of free throw shot. Revista de Psicología del Deporte, 23, 77-85.

Gómez, M.A.,Avugos, S., Oñoro, M., Lorenzo,A., \& Bar-Eli, M. (2018). Shaq isnotalone: Free throws in thefinal moments of abasketball game. Journal of Human Kinetics, 13, 135-144. https:/ /doi.org/10.1515/hukin-2017-0165.

Gómez,M.A., Kreivyte, R., \& Sampaio,J.(2017). Short-andlongterm effects of using shooting straps on free throw accuracy of youngfemale basketball players. Kinesiology,49, 1-10.

Gorospe, G., \& Anguera, M.T. (2000). Retrospectivity in polar coordinates analysis:Application to tennis. Psicothema 12, 279 282.

Lapresa, D., García, J.,Arana,J., \& Garzón, B. (2011).Analysis of time patterns in preshooting gestural routines in basketball free-throw shooting by children 11 to 12 years old. Revista de Psicología del Deporte, 20, 383-400.

Lefebvre, J., Turnnigde, J., \& Côte, J. (in press). A systematic observation of coach leadership behaviours in youth sport. Journal of Applied Sport Psychology.https: / /doi.org/10.1080/ 10413200.2019.1609620

Maglott, J., Chiasson, D. \& Shull, P. (2019). Influence of skill level on predicting the success of one's own basketball free throws. PLoS One, 14, e0214074. https://doi.org/10.1371/ journal.pone.0214074

Magnusson, M. S, Burfield,I., Loijens, L., Grieco,F., Jonsson, G., \& Spink,A. (2004). Theme:Powerful tool for detection and analysis of hidden patterns in behavior. Wageningen, Netherlands: Noldus InformationTechnology.

Memmert,D. (2006). Long-term effects of type of practice on the learning and transfer of a complex motor skill. Perceptual and Motor Skills, 103(3), 912-916. https://doi.org/10.2466/ pms.103.3.912-916

Miller, S., \& Siegel,T. (2017).Youth sportsandphysical activity:The relationship between perceptions of childhood sport experience and adult exercise behavior. Psychology of Sport and Exercise, 33, 85-92. https://doi.org/10.1016/ j.psychsport.2017.08.009

Mullineaux, D., \& Uhl,T. (2010). Coordination-variability and kinematics of misses versus swishes of basketball free throws. Journal of Sports Sciences, 28, 1017-1024. https://doi.org/
10.1080/02640414.2010.487872

Okazaki,V., Rodacki,A., \& Satern, M. (2015). A review on the basketball jump shot. Sports Biomechanics, 14, 190-205. doi:10.1080/14763141.2015.1052541

Okubo,H., \&Hubbard, M. (2015). Kinematicsofarm jointmotions in basketball shooting. Procedia Engineering 112, 443-448. https://doi.org/10.1016/j.proeng.2015.07.222

Oudejans, R., Karamat, R., \& Stolk, H. (2012). Effects of actions preceding the jump shot on gaze behavior and shooting performance in elite female basketball players. International Journal of Sports Science \& Coaching, 7, 255 267. https://doi.org/ 10.1260/1747-9541.7.2.255

Palmer, H., Newell, K., Gordon, D., Smith, L., \&Williams, G. (2018). Qualitative and quantitative change in the kinematics of learning a non-dominant overarm throw. Human Movement Science, 62, 134-142.https://doi.org/10.1016/ j.humov.2018.10.004

Pérez-Tejera,F.,Valera,S., \&Anguera,M.T.(2019). Usingsystematic observation and polar coordinates analysis to assess genderbased differencesin parkuse in Barcelona. Frontiers in Psychology, 9,2299.https://doi.org/10.3389/fpsyg.2018.02299

Piñar,M.I., Cárdenas,D., Conde,J.,Alarcón,F., \& Torre,E. (2007). Satisfactionin minibasketball players. Iberian Congress of Research Basketball, 4, 122-125.

Przednowek, K., Krzeszowski,T., Przednowek, K., \& Lenik, P. (2018). A system for analysing the basketball free throw trajectory based on particleswarm optimization. Applied Sciences, 8, 2090. https: / /doi.org/10.3390/app8112090

Regimbal, C., Deller,J., \& Plimpton, C. (1992). Basketball size as related to children's preference, rated skill and scoring. Perceptual and Motor Skills, 75(3), 867-872.https:/ /doi.org/10.2466/ pms.1992.75.3.867

Sackett, G. P. (1980). Lag sequential analysis as a data reduction technique in social interaction research. In D. B. Sawin, R. C. Hawkins, L. O. Walker, \& J. H. Penticuff(Eds.), Exceptional infant.Psychosocial risks in infant-environment transactions (pp. 300340). NewYork: Brunner/Mazel.

Satern, M. N., Messier, S. P., \& Keller-McNulty, S. (1989). The effects of ball size and basket height on the mechanics of the basketball free throw. Journal of Human Movement Studies, 16, 123137

Tran, C., \& Silverberg,L. (2008). Optimal release conditions for the free throw in men's basketball. Journal of Sports Sciences, 26, 1147-1155. https://doi.org/10.1080/ 02640410802004948

Urbán,T., Caballero, C., Barbado, D. , \& Moreno, F. J. (2019). Do intentionality constraints shape the relationship between motor variabilityand performance?PLoSOne, 14,e0214237.https: / /doi.org/10.1371/journal.pone.021423

Verhoeven, F., \& Newell, K.(2016). Coordinationand control of posture and ball release in basketball free throw shooting. Human Movement Science, 49, 216-224.https://doi.org/ 10.1016/j.humov.2016.07.007 